\title{
Advocating for Health Promotion Policy in Norway: The Role of the County Municipalities
}

\author{
Elisabeth Fosse $^{1, *}$ and Marit Helgesen ${ }^{2}$ \\ 1 Department of Health Promotion and Development, University of Bergen, Christiesgate 13, \\ 5020 Bergen, Norway \\ 2 Norwegian Institute for Urban and Regional Research (NIBR), Oslo and Akershus University College of \\ Applied Sciences, PO BOX 4 St. Olavs plass, NO-0130 Oslo, Norway; Marit.Helgesen@nibr.hioa.no \\ * Correspondence: Elisabeth.Fosse@uib.no; Tel.: +47-55-58-27-58
}

Academic Editor: Kristine Crondahl

Received: 30 January 2017; Accepted: 10 April 2017; Published: 12 April 2017

\begin{abstract}
Background: The Norwegian National government has developed public health policies that reflect health promotion principles, and these are particularly reflected in the recent Public Health Act (PHA). The counties (CMs) have been given a central role in the implementation of the PHA, and in this paper we explore how the CMs fill this role. Methods: Qualitative as well as quantitative data have been applied; a survey, a document study and personal interviews have been conducted. Results: The findings show that the CMs find it challenging to influence all sectors to change the focus from classical lifestyle issues to a focus on the social determinants of health. The Directorate of Health has the main responsibility for implementing the PHA, but the signals from the Directorate are not always consistent. The Directorate still launches campaigns and interventions to improve diets and stimulate physical activity, without launching them in the context of the PHA. Conclusion: The CMs regard the supporting role toward the municipalities as their highest priority. However, they find it hard to anchor and integrate the principles of the PHA. They explain this partly with the sectorised government organisation.
\end{abstract}

Keywords: health promotion; health in all policies; equity in health; governance; implementation

\section{Introduction}

Norway is one of the so-called social democratic welfare states, as classified by Esping-Andersen [1]. The "social democratic" regime is characterised by its emphasis on solidarity and universalism, and the redistribution of resources among social groups, mainly through a progressive tax system and entitlements to vulnerable groups. Action on the social determinants of health was an important element in the building of the Norwegian welfare state, and housing, education, and labour market policies were regarded as instruments in public health policy, as well as a means to develop universal welfare and reduce social inequalities. However, in the 1960s and 70s, public health increasingly included mostly individual measures, and lifestyle interventions became more predominant [2-5].

Over the last decade, the Norwegian national government has developed public health policies that reflect the Health promotion principles, as they are outlined in the Ottawa charter, particularly by addressing social inequity in health [6]. A Government White paper on social inequalities in health entitled National Strategy to Reduce Social Inequalities in Health was released in February 2007 [7] It had a ten-year perspective for developing policies and strategies to reduce health inequities. One main point of the White Paper is that "Equity is good public health policy". This implies a view on public health policies that aims at a more equal distribution of positive factors that influence health. 
The health promotion elements of the Norwegian public health policy are particularly reflected in the Public Health Act (PHA) that was adopted in 2012 [8]. The PHA establishes a new foundation for strengthening the systematic public health work and the development of policies and planning for societal development based on regional and local challenges and needs. In the proposition underlying the Act, it is stated that: "Only by integrating health and its social determinants as an aspect of all social and welfare development through intersectoral action, good and equitable public health can be achieved" [8].

Reducing social inequalities in health by addressing the social gradient is a main aim of the PHA. The gradient approach to policy action comprises broad universal measures combined with targeted (proportionate) strategies for disadvantaged groups; this is termed 'proportionate universalism' [9]. A gradient approach to policy also necessitates a focus on the upstream determinants of health inequities (such as income, education, living, and working conditions) [10,11].

The principle of "Health in all policies" (HiAP) implies that equitable health systems are important to public health, but health inequities arise from societal factors beyond health care [12-14]. HiAP addresses the effects on health across all policies such as agriculture, education, the environment, fiscal policies, housing, and transportation. It seeks to improve health through structures, mechanisms and actions planned and managed mainly by sectors other than health. This implies that the impact on health must be considered when policies and action are developed and implemented in all sectors.

The PHA embraces the idea of HiAP. In governance terms, one of its main features is that it places the responsibility for public health work as a whole-of-government responsibility rather than a responsibility for the health sector alone. Municipalities, county authorities, called county municipalities (CMs), and central government authorities are all considered important actors in the efforts to promote public health and reduce social inequalities in health. The PHA shall ensure that municipalities, CMs and central government health authorities implement measures and coordinate their activities in the area of public health work. Based on local assessments of the public health challenges, public health policy development must be an integrated part of ordinary societal and spatial planning and administration processes in counties and municipalities.

Even though municipalities have the main responsibility for implementing health promotion policies at the local level, the CMs have been given a central role as coordinators and advocates towards the municipalities. The PHA thus demands intersectoral collaboration to a wide extent. In this paper, we will explore how the CMs fill their role as coordinators and facilitators.

\subsection{CMs in the Norwegian Governance System}

In Norway, 428 municipalities and $19 \mathrm{CMs}$ have the overall responsibility for welfare provision. This includes person-centred services, culture, agriculture, climate policies, transport and the development of local areas, industry and jobs. CMs have responsibilities within public administration, service provision, regional development and planning, and they are assigned with the tasks of planning for the development of their region [15-17].

$\mathrm{CMs}$ are public authorities and are autonomous in their relations to the County Governor, the national state representative at the regional level, and the municipalities within their jurisdictions [17]. The aim of the CM planning activity is to produce a planning strategy reflecting politically-stated goals, and they are also mandated to coordinate stakeholders and decide on other CM plans to be made. Examples include plans on regional development and public health. Particularly, the aims of the PHA demand collaboration between a wide range of public and non-public stakeholders.

In 2004, the Directorate of Health established a program in which the CMs role to initiate and facilitate municipal public health policies was stated. The CMs were invited to join in partnerships with the Directorate, and in 2008 all had joined in. At the same time, CMs were to invite municipalities in their county to enter partnerships. The CM partnership mechanisms included funding for the municipalities to improve their efforts in developing health promotion policies. Among the measures were the employment of Public Health Coordinators and the development of the local planning 
systems. During these years, the CMs built an administration and public health coordinators or advisors were employed even at this level [18].

\subsection{HiAP and Social Equity-The "New" Concept of Public Health}

HiAP challenges the so-called siloed bureaucratic government structure, where each department is responsible only for policies and measures within its own field (health, education, infrastructure etc.). This is particularly problematic in an increasing number of fields, which demands action from many sectors of society [19-21]. HiAP therefore should be regarded as a set of institutional arrangements to achieve more intersectoral collaboration [22]. The PHA is the most distinctive of the institutional arrangements, especially concerning the requirement of CMs and municipalities to develop overviews over positive and negative factors determining health. Further institutional arrangements are the establishment of intersectoral working groups and the employment of public health coordinators or advisors [23]. Planning is regarded as a vital strategy to anchor and integrate health promotion policies and measures both at the $\mathrm{CM}$ and municipal levels. The prioritization of these institutional arrangements in many ways represents the "new" public health policies, moving in the direction of health promotion.

The data from the current paper was collected as part of a larger project, where the main aim was to study the implementation of the Norwegian public health policy in the municipalities. The project applied a mixed methods approach. Data consist of two surveys to all municipalities in 2011 and 2014. The study participants were administrative leaders in all municipal sectors. The main focus was on how the municipalities organised their policies regarding HI and HiAP. The questions included whether the municipalities had employed public health coordinators, whether they had included social inequality as part of their planning system, whether they had establishes inter-sectoral working groups, etc. Furthermore, six municipalities take part in a qualitative study. Policy-makers and administrative leaders were interviewed about the development of the public health work in their respective municipalities, by following up on the questions from the surveys.

The surveys showed that the municipalities to a small extent had adopted the principles of HiAP and HI $[23,24]$. Many municipalities focused mainly on lifestyle- and health care-related measures. The findings identified a divide between the national policies and the strategies adopted at the municipal level to implement the PHA [16]. Municipalities which has started the implementation of the Act were included in the qualitative interview studies. Even these studies showed differences between the municipalities. Some municipalities still prioritised individual lifestyle measures, while others were in the process of integrating the policies across sectors [25]. The findings indicate that there is raised awareness of the significance of social determinants among an increased number of municipalities and that they are in the process of developing policies specifically to level the social gradient in health.

Research also shows that the CMs have developed many measures to strengthen public health [26]. The approach varies between the CMs, but there seems to be a strategic commitment, which is illustrated by the fact that health promotion is being included in the planning strategies of the CMs.

In this paper, we will study how the CMs implement the aims of the PHA regarding the overall aims of improving equity by addressing social inequalities and applying an HiAP approach. Our main research question is:

How are the counties equipped to act as advocates for health promotion and particularly HiAP? To answer this, we ask the following questions: How is health promotion policy included in county plans? How is HiAP carried out at the county level? What are the priorities of CMs in supporting the municipalities? To what extent do governance signals from the national level reflect the HiAP approach?

\section{Materials and Methods}

Qualitative as well as quantitative data have been applied; a survey, a document study and personal interviews have been conducted in the collection of data. The survey data includes all $19 \mathrm{CMs}$. 
The survey was sent to 903 politicians and top administrators as part of the project Countynode. 289 of them answered questions on participation in a diverse set of coordinative and planning activities. The response rate was $32 \%$, and among the respondents were 232 politicians and 56 top administrators. The actual question referred to here is: "Which actors do you consider important to mobilise on the following policy areas?" The question was a matrix, and 102 ticked for mobilizing the actors according to public health policy while 193 ticked for mobilizing them according to regional development.

The document analysis was undertaken as part of a masters' degree in health promotion and is presented in a masters' thesis, and the data consisted of public health plans developed by the CMs [27]. The counties were not mandated to develop public health plans, but 13 of 19 counties had developed such plans and the document study included these counties. The content of the plans was analysed to document whether the CMs were giving priority to the overall aims of the PHA; reducing HI by applying an HiAP approach. Five of the CMs had reducing HI as their overall aim, while seven did not have this as a main aim. One CM plan did not have an overall aim. In this paper, we have used the findings from the thesis as background material to show the overall situation regarding planning in the CMs.

Individual interviews were conducted with policy-makers from three CMs. The CMs were sampled strategically, and the main inclusion criterion was that they had already started the process of implementing the PHA, particularly by addressing HI and the principles of HiAP. In each CM, between five and nine informants were interviewed. Our contact persons were a public health advisor/coordinator in each of the CMs and, on their advice, we included policy-makers who were involved in public health. The CMs selected had different organisational models, and therefore the relevant informants varied to some extent. In general, political and administrative leaders and leaders of different sectors or units were interviewed along with public health coordinators. The aim of this paper is not to compare the CMs; the interview data and quotes aim to present an in-depth and nuanced picture. The interviews were transcribed verbatim and analysed by applying thematic content analysis.

The different data sources were used to triangulate and validate the findings. The survey provided data from many policy-makers and contributed to the broader picture of public health work in the CMs. The document study showed the status of the public health planning process, while the interviews provided policy-makers' experiences and reflections.

The study is mainly a qualitative study and as such the findings cannot be statistically generalised. It is also possible that we could have had other findings if we had chosen different CMs. However, the survey and the document analysis provides a background picture that improves the reliability and validity of the study. Both the document study and the interview study received ethical approval from the Norwegian Data Protection Official for Research, while the survey did not need ethical approval.

\section{Results: How Is HiAP Carried out at the County Level?}

Public health has traditionally been the responsibility of the health sector, but this changed with the PHA and all sectors are now held responsible. Another areas that the CMs are responsible for is regional development, which is a theme that has had a clear intersectoral profile over many years since, in principle, it covers many sectors and areas. We were therefore interested to compare the regional development area to the public health area to get an impression of whether public health is being understood as a field that demands intersectoral collaboration and participation.

As can be seen from Figure 1, more respondents answered the question concerning regional development than the question on public health. Generally, those who answered for public health considered it less important to mobilize actors across several sectors than those who answered for regional development. In both policy areas, $63 \%$ of $\mathrm{CM}$ politicians and leading officers define other $\mathrm{CM}$ sectors to be of importance to mobilize horizontally. Furthermore, mobilizing voluntary organizations are considered much more important for public health than for regional development. The mobilization of the County Governor, other regional authorities, working life organizations and private businesses 
are considered much more important to regional development than to public health. The findings show that the respondents consider it more important to achieve intersectoral collaboration in the field of regional development than in public health. This may indicate that the principles of the PHA have not been fully understood by the CMs.

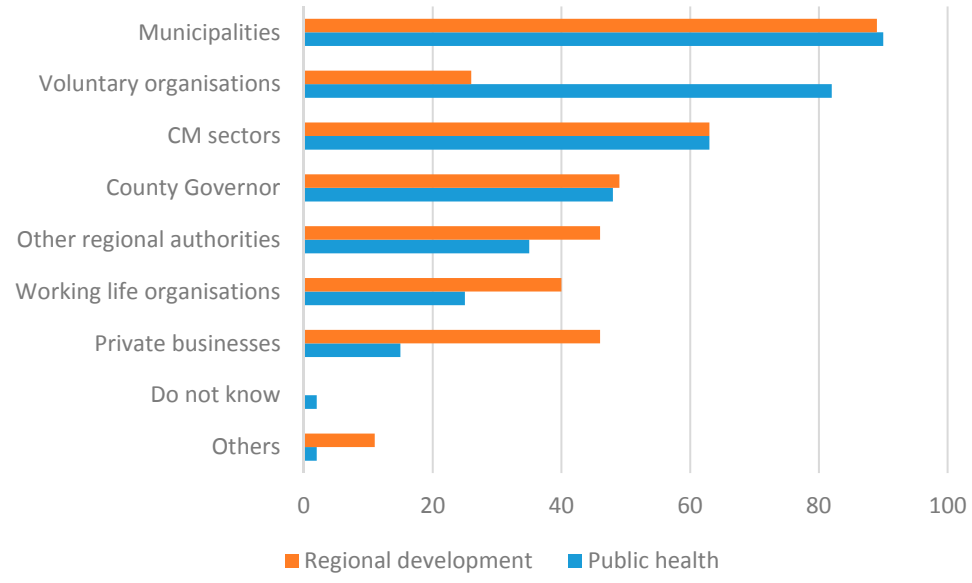

Figure 1. Actors considered important to mobilize on the two policy areas. Percent. $(\mathrm{N}=$ public health: 102, regional development: 193).

\subsection{How Is Health Promotion Policy Included in County Plans?}

Shandiz [27], studied how the CMs addressed the main health promotion principles of the PHA; reducing inequities in health by levelling the social gradient, and applying an HiAP approach. The study took its point of departure in the CMs that had developed regional public health plans. The rationale for this approach was that, at both regional and local levels, developing plans is considered essential by the national government for anchoring and integrating health promotion in policies and services [8]. Even if it was not mandatory for CMs to develop health promotion plans, it provides an indicator of how equity and HiAP was implemented. Thirteen of $19 \mathrm{CMs}$ had developed such plans, and the findings showed that the CMs that had published plans also included equity issues and applied an HiAP approach. However, in their priorities of policies and strategies, there were few measures that aimed at addressing equity issues or the social gradient. The plans mostly reflected a perspective where equity issues meant addressing socially disadvantaged groups rather than the social gradient.

The findings also indicate that the CMs acknowledge that health promotion demands intersectoral collaboration. This is also reflected in the measures developed by several CMs. Still, measures addressing lifestyle issues such as physical activity and diet were more predominant than measures that addressed the social determinants of heath. Lifestyle interventions are traditionally a main responsibility of the health sector and do not clearly reflect an understanding based on an HiAP approach.

In the following, we will present results from personal interviews with policy-makers in three CMs to obtain a deeper understanding of how the principles of HiAP and equity are being addressed.

\subsection{How Is HiAP Carried out at the County Level?}

The CMs each had a different history in developing and applying HiAP. In one of the CMs, the head of the Development department stated that the CM had applied an HiAP perspective even before the PHA:

"We had that even before the Act. But we have of course become much more aware of the role of the CM should have, and the role of the County Governor and the municipalities. But one thing is to know your role, a different matter is implementation and to include it in everything we do." 
This informant goes on to tell that implementation has been difficult, but that they have taken the point of departure in concrete projects:

"We have been working on a traffic security project that involves several sectors and we collaborate with the dental services. We aim to present the good examples, but it is not always easy. But we have lifted it to the leadership level, that is important."

In this $\mathrm{CM}$, the public health advisor confirms that it has been challenging to integrate a new understanding of public health, in line with health promotion principles:

"It is a challenge, the old understanding of public health was related to physical activity and diet, and these are the themes the CM used to work with, and the new understanding is difficult to integrate."

This CM has developed a regional plan for health promotion, and the same informant sees the plan as a vehicle for the implementation of the PHA:

"I am very happy that we have developed a strategy, a regional plan, which means that we already have integrated the new public health work at the strategic leadership level."

A public health advisor from a different $\mathrm{CM}$ emphasized the importance of having the PHA:

"Having the Act that states how it is going to be and provides us with a hammer we can bang on somebody's head, we can make them accountable."

A third public health advisor pointed to the challenge of gaining attention in other sectors and influencing them to make the same priorities:

"Over the years, I have worked with public health, much has happened, but it is difficult to get attention, it is always a struggle for attention. You must be an advocate, also within your own sector."

This informant also addresses the complexity of the new public health concept, and the implications for intersectoral collaboration:

"We involve and try to influence other sectors, and their ordinary tasks. This is the difficult part; what should be defined as public health and what is not public health?"

That the process of defining public health and HiAP has been demanding is confirmed by other informants:

"In the beginning, we did not understand one another. First, we had to define public health, and we have spent much time on that. Then we had to challenge each other to see things in a new way and in a broader context."

\subsection{What Are the CMs' Priorities in Supporting the Municipalities?}

In addition to implementing the principles of HiAP and equity in their own organisations, the CMs also have a role as advocates and facilitators towards the municipalities. As we have seen above, this task is not so new for them; in the partnership agreements that existed before the PHA this role was also important. After the Act was adopted, the focus is more on the implementation of the Act and the municipal planning process has gained an important focus. This is also reflected in the interviews:

"We read and comment on municipal plans, these plans are sent to us."

Another informant states that the planning process has gained more interest and has become more important in the contact between the county and the municipalities:

"Earlier nobody asked what results came out of the planning process, and the focus was on each sector, not on the collaboration between sectors and what the end results were. I now work mostly with chief executive officers (CEOs) and the planning departments, we assist them in the planning process and assist them in getting all sectors involved." 


\subsection{To What Extent do Governance Signals from the National Level Reflect the HiAP Approach?}

The PHA presupposes that both horizontal and vertical integration is important for a successful implementation of the PHA. The national level provides the institutional and legal framework for the Act, and plays an important role in supporting and facilitating the implementation at the county and municipal levels.

The Directorate of Health is responsible for facilitating the implementation and coordinating efforts towards counties and municipalities. Research shows that the Directorate has taken on this responsibility $[16,28]$. However, the Directorate is a large, bureaucratic organization and the PHA is one among their many responsibilities, and other departments in the Directorate also communicate with the CMs and the municipalities. The signals given are not always coordinated and particularly lifestyle-related programs, that first and foremost are a responsibility of the health sector, may be a competing message. These programs are often coordinated by the CMs and may even be in competition with the PHA. One of the informants describes this as a problem:

“The PHA is so new, you have to work hard for it to have power, I don't think it has that much influence yet. What I miss is clearer signals from the Directorate."

This informant states that much of the communication from the Directorate of Health to the municipalities is about traditional lifestyle issues:

“The Directorate still talks about physical activity, diet and a little bit about alcohol, and tries to say something about mental health. This does not contribute to an understanding of the new public health in the municipalities, particularly not for the CEO and his staff."

This informant also misses a stronger collaboration between national government departments and directorates from different sectors:

“They don't play on the same team; they don't really collaborate. There is no coordination at the top, and then there is no coordination further down in the hierarchy. They expect us to walk into each other's offices and talk. They don't give any prescriptions for what we should coordinate and how."

These quotes indicate that there is also a way to go in intersectoral coordination at the national level, and that the bureaucratic silos still represent an obstacle for the implementation of an HiAP approach.

\subsection{Summary of Findings}

There are some main points that can be drawn from the data presented in this paper. The first may be associated with the findings from the CountyNode project, that showed that policy-makers in the CMs found it more important to implement intersectoral collaboration in the field of regional development than in public health. This seems to support other findings indicating that the consciousness about the "new" public health had not yet found a solid holding. The document study included the $13 \mathrm{CMs}$ that developed public health plans and, even if many of them addressed issues of social inequalities, few had developed intersectoral policies to meet these challenges. The interviews provided a deeper understanding of the processes, and the factors that may promote or prevent the implementation of the PHA at the county level. These will be elaborated below in the discussion section.

\section{Discussion}

Our main research question asked whether the CMs are equipped to act as advocates for health promotion. Over the last decade, they have been given an increasingly important role and they are responsible for several areas related to health promotion. They are mandated to develop policies 
to be followed up with plans, policies and measures. They have received resources to build up an administration, including employing public health advisors. Even more important, they have a very strong role as facilitators and advisors towards the municipalities. Over several years before the PHA was adopted, they could support municipalities economically to stimulate the building of health promotion structures. In this sense, the $\mathrm{CMs}$, in principle, seem to be well equipped to address the new themes of health equity and HiAP.

The CMs are not mandated to develop health promotion plans but still the majority of them have developed such plans. The plans also include aims to reduce health inequalities through intersectoral collaboration. However, many of the concrete measures suggested are interventions within the traditional public health areas; diet, physical activity and other lifestyle issues [27].

Health promotion in the PHA is not about programs and intervention, but about developing policies. The principles of health promotion should thus be integrated in all sectors. Public health advisors have the most important role in coordinating health promotion in the CMs, and the interviews show that they find it challenging to influence both their own and other sectors to change the focus from the classical lifestyle issues to a focus on the social determinants of health.

The new health promotion-inspired concept is complex and it is not always easy to argue why living conditions and social inequality are part of a health concept. It may also be demanding to include these issues in the planning process as a first step to develop policies and measures further on in the policy process. Furthermore, the CMs are responsible for several policy areas, and the CMs report that there is a competition for attention between the different areas and sectors. Health promotion might not necessarily win this competition.

The municipalities are mandated to include health promotion perspectives in the local planning process. This emphasis on planning as an important vehicle in developing health promotion policies was introduced in the PHA, and it might be difficult for the municipalities to shift the focus from individual lifestyle issues to including public health in the policy process. Other research has shown that the municipalities have struggled to integrate health promotion in their planning processes. In a survey conducted in 2014, only $25 \%$ of the municipalities reported that they had conducted the overview of the health situation in their municipality that would serve as the data basis for the plan [24].

Our findings indicate that the role of supporting the municipalities in their planning process is regarded the most important priority for the CMs. The services that are important to reducing social inequalities are to a large degree a responsibility of the municipalities. In a determinant perspective, these are, for example, schools, day care institutions, and leisure time activities, but also include departments that are responsible for the environment and infrastructure.

However, the PHA is a national act, and the signals coming from the national level will of course influence implementation in CMs and municipalities [29]. The Directorate of Health has the main responsibility for implementing national goals in public health. The Directorate is a large institution with many department with responsibilities within different sectors. The CMs report that the signals from the Directorate are not always consistent. The Directorate still launches campaigns and interventions to improve diets and stimulate physical activity, without launching them in the context of the PHA. The CMs' impression is that there is little coordination between the initiatives coming from the Directorate, and that even within the Directorate there are silos. This may also create confusion, since the main message of the PHA is based on the determinant perspective and not individual lifestyle change.

In this sense, it seems that the silos of public administration create one of the major problems for integrating health promotion principles in the implementation of the PHA. Carey and Crammond apply the term "joined up government" to characterize themes that are multi-sectoral in character [22]. According to them, integration must happen at multiple levels and be supported by a range of cultural and structural interventions. It is important to witness commitment and leadership at all levels, 
from the political level to the practitioners. In other words, there needs to be a process where both top-down as well as bottom-up initiatives are prioritised.

\section{Conclusions}

The Norwegian PHA is ambitious, as it has introduced health promotion as guiding principles in public health, with a particular aim of reducing social inequalities in health by taking actions to change the social gradient. The PHA is a truly local act, as the CMs and municipalities have the main responsibility for implementing policies and measures to level the social gradient in health though HiAP strategies. This will demand changes in focus and priorities, and the local planning process has been regarded as the first important step to integrate health promotion in policies and measures. In the present paper, we have reported the situation in some CMs. The CMs regard the supporting role toward the municipalities as their highest priority. However, they find it hard to anchor and integrate the principles of the Act. The CMs have many tasks and they are not coordinated, and the HiAP approach is not self-evident, as this is a term developed by the health sector. Also, the initiatives from the Directorate of Health did not seem to be well-coordinated, and this makes the process of integrating the principles of reducing social inequalities by applying a HiAP approach at the $\mathrm{CM}$ and municipal levels a more demanding task.

Acknowledgments: The research presented in this paper is funded by the Norwegian Research Council as part of the projects: Addressing the social determinants of health: Multilevel governance of policies aimed at families with children (SODEMIFA) (Project No. 213841/H10) and CountyNode (Project No. 220572). Thanks to Karina Nummedal Shandiz, who wrote a Master's thesis where she analysed county plans as part of the project.

Author Contributions: The research presented in this article is based on data from two projects. Fosse and Helgesen were both researchers in the SODEMIFA project. Fosse performed the interviews and analyses of the data used in this project. Helgesen collected and analysed the data based on the CountyNode project. Both authors have contributed to the writing of the article.

Conflicts of Interest: The authors declare no conflict of interest.

\section{References}

1. Esping-Andersen, G. The Three Worlds of Welfare Capitalism; Polity Press: Cambridge, UK, 1990.

2. Dahl, E. Health inequalities and health policy: The Norwegian case. Norsk Epidemiol. 2002, 12, 69-75. [CrossRef]

3. Fosse, E. Norwegian public health policy-Revitalisation of the social democratic welfare state? Int. J. Health Serv. 2009, 41, 255-272. [CrossRef] [PubMed]

4. Fosse, E. Norwegian Health Promotion policy: The pendulum swings of 1984 to 2007. In An Ecological Perspective on Health Promotion: Systems, Settings and Social Processes; Samdal, O., Wold, B., Eds.; Bentham Science Publishers: Emirate of Sharjah, UAE, 2012.

5. World Health Organization (WHO). Closing the Gap in a Generation. Health Equity through Action on the Social Determinants of Health; Final Report Commission on the Social Determinants of Health; Word Health Organization: Geneva, Switzerland, 2008.

6. The Ottawa Charter for Health Promotion; WHO: Geneva, Switzerland, 1986.

7. National Strategy to Reduce Social Inequalities in Health; Report to the Storting No. 20 (2006-2007); Norwegian Ministry of Health and Care Services: Oslo, Norway, 2007.

8. Ministry of Health and Care Services. Public Health Act, No. 29, 24-06-2011; Ministry of Health and Care Services: Oslo, Norway, 2011.

9. Marmot, M. The Marmot Review. Fair Society, Healthy Lives. Strategic Review of Health Inequalities in England Post-2010; Department of Health: London, UK, 2010.

10. Graham, H. Tackling inequalities in health in England: Remedying Health Disadvantages, narrowing Health Gaps or Reducing Health Gradients? J. Soc. Policy 2004, 33, 115-131. [CrossRef]

11. Marmot, M. Achieving health equity: From root causes to fair outcomes. Lancet 2007, 370, 1153-1163. [CrossRef] 
12. Leppo, K.; Ollila, E.; Peña, E.; Wismar, M.; Cook, S. Health in All Policies. Seizing Opportunities, Implementing Policies; Finnish Ministry of Social Affairs and Health: Helsinki, Finland, 2013.

13. Melkas, T. Health in all policy as a priority in Finnish health policy: A case study on national health policy development. Scand. J. Public Health 2013, 41, 3-28. [CrossRef] [PubMed]

14. Ståhl, T.; Wismar, M.; Ollila, E.; Lahtinen, E.; Leppo, K. Health in All Policies. Prospects and Potentials; Ministry of Social Affairs and Health, Finland and European Observatory on Health Systems and Policies: Helsinki, Finland, 2006.

15. Higdem, U. Regional planlegging. In Utfordringer for Norsk Planlegging. Kunnskap, Bærekraft, Demokrati; Aarsæther, N., Ed.; Cappelen Damm Høyskoleforlaget: Oslo, Norway, 2013.

16. Tallarek, M.G.; Helgesen, M.K.; Fosse, E. Reducing social inequalities in health in Norway: Concerted action at state and local levels? Health Policy 2013, 13, 228-235. [CrossRef] [PubMed]

17. Kleven, T. Fra Gjenreisning til Samfunnsplanlegging. Norsk Kommuneplanlegging 1965-2005; Tapir Akademisk Forlag: Trondheim, Norway, 2011.

18. Hofstad, H.; Hanssen, G.S. Samfunnsutviklerrollen til Regionalt Folkevalgt Nivå. Videreutvikling av Rollen Gjennom Partnerskapsbasert Regional Utvikling og Planlegging; NIBR Report 2015:17; Norwegian Institute for Urban and Regional Research: Oslo, Norway, 2015.

19. Hjern, B. Samverkan-Inneord eller en utmaning för den svenska modellen. In Folkhälsa i Samverkan Mellom Professioner, Organisationer och Samhällssektorer; Axelsson, R., Axelsson, S.B., Eds.; Studentlitteratur: Uppsala, Sweden, 2007.

20. Axelsson, R.; Axelsson, S.B. Integration and collaboration in public health-A conceptual framework. Int. J. Health Plan. Manag. 2006, 21, 75-88. [CrossRef]

21. Carey, G.; Crammond, B. What Works in Joined-Up Government? An Evidence Synthesis. Int. J. Public Adm. 2015, 38, 1020-1029. [CrossRef]

22. Carey, G.; Crammond, B.; Keast, R. Creating change in government to address the social determinants of health: How can efforts be improved? BMC Public Health 2014, 14, 1087. [CrossRef] [PubMed]

23. Hagen, S.; Helgesen, M.; Torp, S.; Fosse, E. Health in All Policies: A cross-sectional study of the public health coordinators' role in Norwegian municipalities. Scand. J. Public Health 2015, 43, 597-605. [CrossRef] [PubMed]

24. Hagen, S.; Torp, S.; Helgesen, M.; Fosse, E. Promoting health by addressing living conditions in Norwegian municipalities. Health Promot. Int. 2016. [CrossRef] [PubMed]

25. Fosse, E.; Helgesen, M.K. How can local governments level the social gradient in health among families with children? The case of Norway. Int. J. Child Youth Fam. Stud. 2015, 6, 328-346. [CrossRef]

26. Helgesen, M.K.; Hofstad, H.; Risan, L.C.; Stang, I.; Rønningen, G.E.; Lorentzen, C.; Goth, U.S. Folkehelse og Forebygging. Målgrupper og Strategier i Kommuner og Fylkeskommuner; NIBR-Report 2014, 3; Norwegian Institute for Urban and Regional Research: Oslo, Norway, 2014.

27. Shandiz, K.N. Norske Fylkeskommuner-Med Sosiale Ulikheter Og “Helse i Alt Vi Gjør” På Agendaen? Master's Thesis, University of Bergen, Department of Health Promotion and Development, Bergen, Norway, 2015.

28. Strand, M.; Fosse, E. Tackling health inequalities in Norway: Applying linear and non-linear models in the policy making process. Crit. Public Health 2011, 21, 373-381. [CrossRef]

29. Fosse, E. Kommunenes rolle i å utjevne sosiale helseforskjeller-Norge som eksempel. Socialmed. Tidsskr. 2016, 5, 492-500.

(C) 2017 by the authors. Licensee MDPI, Basel, Switzerland. This article is an open access article distributed under the terms and conditions of the Creative Commons Attribution (CC BY) license (http:/ / creativecommons.org/licenses/by/4.0/). 